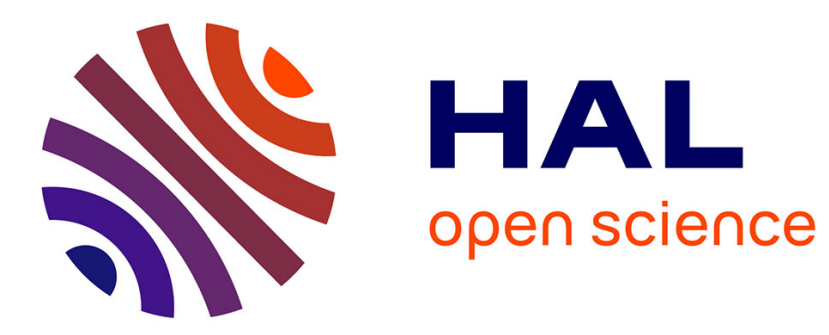

\title{
MODELING AND ANALYSIS OF THE THREAD MILLING OPERATION IN THE COMBINED DRILLING/THREAD MILLING PROCESS
}

\author{
Martin B G Jun, Anna Carla Araujo
}

\section{- To cite this version:}

Martin B G Jun, Anna Carla Araujo. MODELING AND ANALYSIS OF THE THREAD MILLING OPERATION IN THE COMBINED DRILLING/THREAD MILLING PROCESS. 2008 International Manufacturing Science and Engineering Conference MSEC2008, 2008, Evanston, Illinois, United States. hal-03212836

\section{HAL Id: hal-03212836 \\ https://hal.science/hal-03212836}

Submitted on 30 Apr 2021

HAL is a multi-disciplinary open access archive for the deposit and dissemination of scientific research documents, whether they are published or not. The documents may come from teaching and research institutions in France or abroad, or from public or private research centers.
L'archive ouverte pluridisciplinaire HAL, est destinée au dépôt et à la diffusion de documents scientifiques de niveau recherche, publiés ou non, émanant des établissements d'enseignement et de recherche français ou étrangers, des laboratoires publics ou privés. 


\section{MSEC ICM\&P2008-72209}

\section{MODELING AND ANALYSIS OF THE THREAD MILLING OPERATION IN THE COMBINED DRILLING/THREAD MILLING PROCESS}

\author{
Martin B.G. Jun, Assistant Professor \\ Department of Mechanical Engineering, \\ University of Victoria \\ Victoria, British Columbia, Canada
}

\author{
Anna Carla Araujo, Assistant Professor \\ Mechanical Engineering Department \\ CEFET-RJ \\ Rio de Janeiro, RJ, Brazil
}

\begin{abstract}
This paper investigates a thread making process called thrilling, which performs both drilling and thread milling with one tool. A chip thickness and mechanistic cutting force model has been developed for a thread milling operation with a thrilling tool. The model considers the complex geometry of a thrilling tool and the unique tool paths associated with the thread milling operation. Calibration experiments have been conducted to estimate the cutting coefficients associated with specific cutting energies. Experiments have been conducted to validate the developed model. Comparison of the average torque and forces between experiment and simulation results shows that the model predicts the experimental results within $12 \%$ error. The model has also been used to analyze the effects of helix angle and number of engaged threads on the cutting forces.
\end{abstract}

\section{INTRODUCTION}

Threads on a workpiece can be produced in a variety of ways based on two basic principles: plastic working and metal cutting. Threads made by plastic working are stronger but lack the accuracy required for many applications. Threads made by cutting, on the other hand, provide better accuracy and finish and threads can be made even with brittle materials. There are two common cutting processes for internal thread generation: cut tapping and thread milling. Recently, a thread cutting tool called a thriller has been developed [1], which can perform both drilling and thread cutting operations. Thus, after drilling a hole, no tool change is required to make threads, leading rapid thread generation. This elimination of tool change times leads to decreases in tooling cost and increase in process flexibility and material savings. One substantial disadvantage of the process may be its low length to diameter $(\mathrm{L} / \mathrm{D})$ ratio capability due to tool deflection and vibration. Also, the very bottom of a blind hole will not have threads due to the unique design of the thrilling tool. However, little is known about the process mechanics, and this process needs to be understood for effective application of the process.

The bottom of a thrilling tool (thriller) is similar to a drill, and along the helix of the tool has the tool geometry of a thread milling tool. Since one tool performs two different processes consecutively, the geometry of the tool and the mechanics of the process are unique. The quality of the threads generated would depend on the unique characteristics of the tool and the process. However, though thread making processes both based on plastic working [2-5] and thread cutting [6-8] have been extensively studied by many researchers, the thrilling process has not been so investigated. The thrilling process has been experimentally investigated recently [9]. However, no modeling work has been conducted to understand the thread milling operation during the thrilling process.

The objective of this paper is to develop a chip thickness and cutting force model in order to study and predict the performance of the thrilling process as it relates to thread quality. The model considers the complex geometry of a thrilling tool and the unique tool paths associated with the operation done by a thriller. Cutting forces during thrilling are measured and related to the cutting characteristics of the process. Calibration experiments have been conducted to estimate the cutting coefficients associated with specific cutting energies. Experiments have been conducted to validate the developed model. 


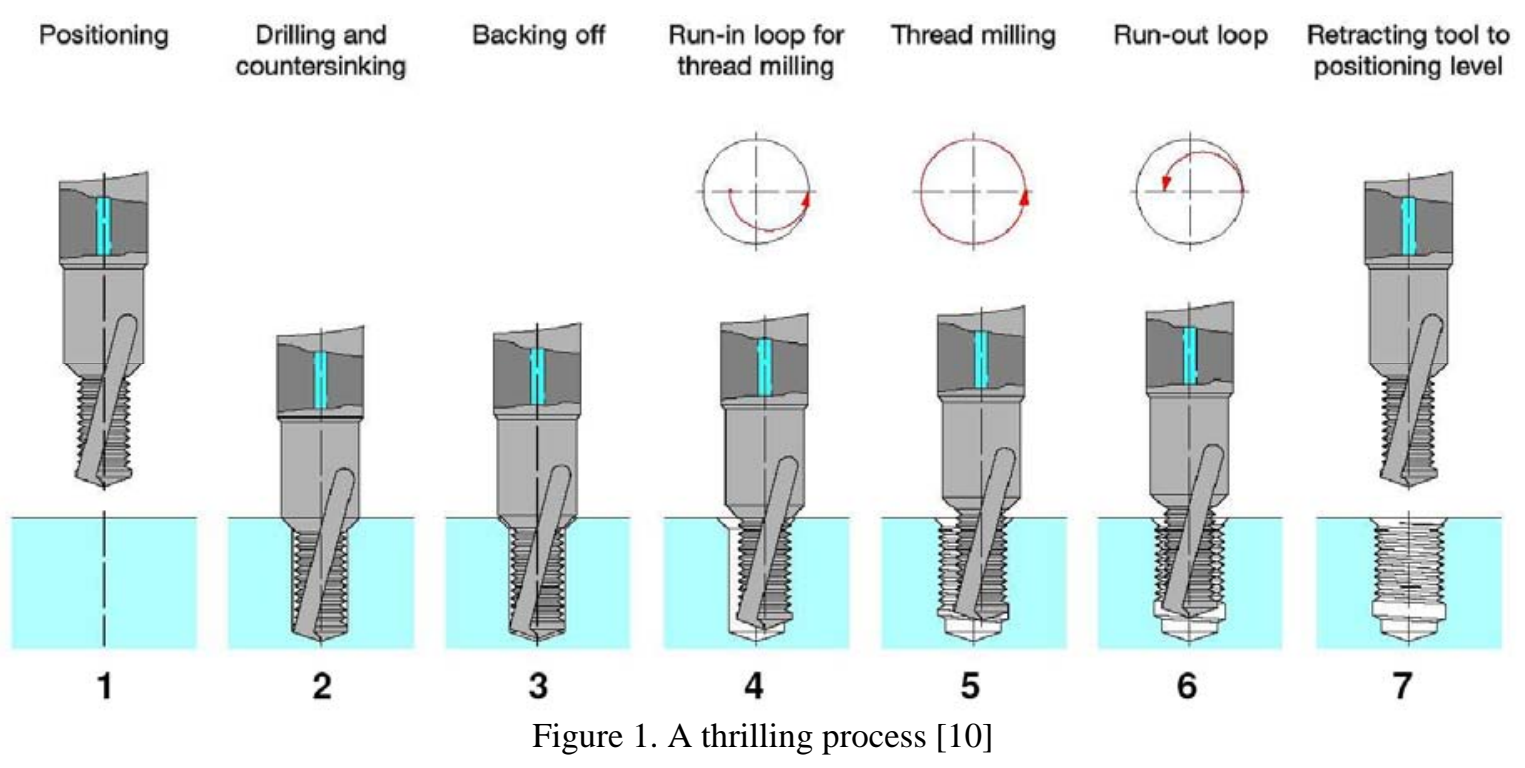

The paper is organized as follows. The unique characteristics of the thrilling process are first described, followed by examination of the tool geometry and tool paths associated with in the thrilling process. Development of the chip thickness and cutting force model is then presented, followed by calibration of the cutting coefficients and model validation. Finally, some analysis of the effects of tool geometry and cutting condition on the cutting forces and conclusions are presented.

\section{PROCESS DESCRIPTION AND TOOL GEOMETRY}

Description of a Thrilling Process. The machining process of thrilling can be divided into seven stages as shown in Fig. 1 [10]. The first stage involves positioning the tool above the workpiece where the hole with threads needs to be made. Once the tool is positioned, it drills down into the workpiece to the desired depth of the hole. Then, the tool retracts up enough so that the cutting lips do not interfere with the thread milling operation. In order to make the thread, while rotating at the prescribed rotational speed and retracting the tool half the pitch, the tool moves radially into the workpiece to a proper radial depth of cut through a helical "run-in loop". Once the cutting edge is engaged into the workpiece at the desired radial depth of cut, the tool moves one complete revolution around the hole in a planetary gear motion, simultaneously moving up helically. The number of threads generated in this one revolution corresponds to the number of threads engaged in the workpiece. Then, the tool moves back to the center of the hole, and, finally, the tool is retracted out of the hole.

Thrilling Tool Geometry. The geometry of a thriller is shown in Fig. 2. Each flute has a chisel edge, drilling cutting lip, milling cutting edge, and thread milling cutting edge. The chisel edge does not cut but only spreads the material sideways by an indentation mechanism [11]. It has a width of $2 w$ and an edge angle of $\psi_{c}$. The cutting lips have an offset from the center of the tool due to the chisel edge. The cutting lips remove the material with a constant chip thickness as the tool is fed into the workpiece at a feed rate of $f_{d}$. The chisel edge and cutting lips have the shape of a drill. The cutting lips at the point angle $\kappa$ and with the height $h_{d}$ meet with the milling cutting edge. The milling cutting edge height is denoted as $h_{m}$.

The milling cutting edge separates the drilling part from the thread milling part. During the drilling stage, the milling cutting edge does not cut but only acts as a helical flute for chip evacuation. Then, the milling cutting edge cuts as a milling tool so that the drilling cutting lips do not interfere with the thread milling operation. During the thread milling operation, the cutting forces generated include the forces due to thread making and also cutting by this milling cutting edge. The external diameter of the thread milling cutting edge is smaller than the milling cutting edge diameter $\left(d_{m}\right)$.

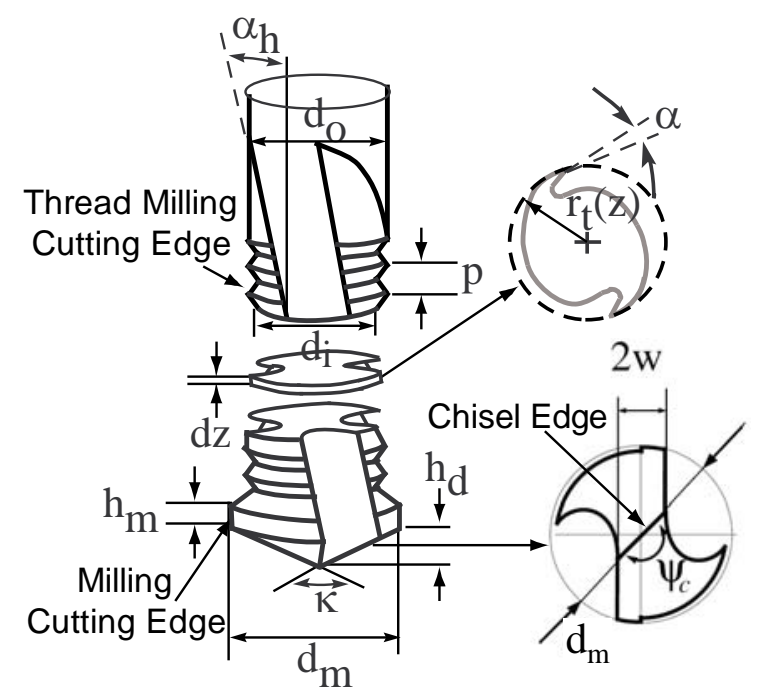

Figure 2. A thrilling tool geometry and discretization 
The threads on a thriller have the maximum diameter on the outside $d_{o}$ and minimum diameter $d_{i}$, which can be obtained as $d_{i}=d_{o}-2 h_{t}$, where $h_{t}$ is the thread height. The thread pitch is denoted as $p$. Figure 3 shows an example of the thread geometry of an M10 thrilling tool. The dashed line shows the height of a M10 thread. The dot-dashed line shows the center of the tool during drilling. Since the drilled hole needs to be greater than the thriller thread diameter, the milling cutting edge radius is greater than the thread tooth height or radius. To make an M10 thread in the workpiece, the distance to be moved into the workpiece during the thread milling operation is equal to the thread height plus the difference between heights of the milling cutting edge and thread tooth. For the thriller in Fig. 3, this distance is equal to $0.9 \mathrm{~mm}$. The position of a fully engaged thriller is shown as a dashed line in Fig. 3.

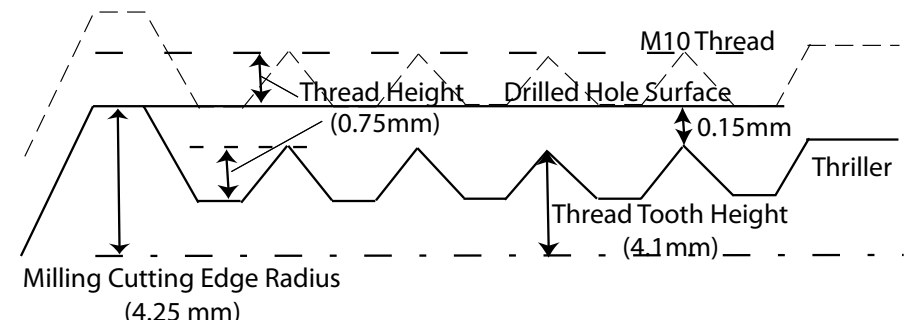

Figure 3. Thriller and thread geometries

The thread milling tool can be analyzed as a stack of disks, 1...Nz, where each disk has $d z$ thickness and a variable radius $r_{t}(z)$ as shown in Fig. 2. The variable diameter $r_{t}(z)$ can be written as a function of the disk height $z$ measured from the bottom of the tool. The radius of each disk element $r_{t}(z)$ can be obtained as

$r_{t}(z)= \begin{cases}z r_{m} / h_{d} & \text { if } 0<z \leq h_{d} \\ r_{m} & \text { if } h_{d}<z \leq h_{d m} \\ r_{i}+3 h_{m}\left(h_{p}-z\right) / p & \text { if } h_{d m}<z \leq h_{p} \\ r_{i} & \text { if } n t\left(z_{p}\right)=0,3,6, . . \\ r_{i}+3 h_{t}\left(z_{p}-n t\left(z_{p} / 3\right) p-p / 3\right) / p & \text { if } n t\left(z_{p}\right)=1,4,7, . . \\ r_{i}+3 h_{t}\left(p-z_{p}-n t\left(z_{p} / 3\right) p\right) / p & \text { if } n t\left(z_{p}\right)=2,5,8, . .\end{cases}$

where $z_{p}=z-h_{p}, h_{p}=h_{d}+h_{m}+3 / p, h_{d m}=h_{d}+h_{m}$, and the function $n t(\xi)$ is defined as

$$
n t(\xi)=\text { IntegerPart }\left(\frac{3 \xi}{p}\right) \text {. }
$$

As will be shown later, this variation in the disk diameter along the tool causes radial depth of cut to vary for each disk. The angle between the flutes depends on the numbers of flutes $N_{f}$ and is defined by the tool geometry as

$$
\theta_{p}=\frac{2 \pi}{N_{f}} .
$$

\section{MODEL DEVELOPMENT}

Since the bottom geometry of a thriller for drilling share the same geometry of a typical drill, the cutting mechanics is the same as in normal drilling. The drilling process has been studied by many researchers and chip thickness and force models have been developed for drilling [12-16]. Thus, modeling of the drilling operation during the thrilling process is not considered in this paper. As the thread milling operation in thrilling involves a unique tool path consisting of run-in, thread-milling, and run-out motions, an accurate modeling of the tool and cutting edge locations is important for chip thickness model development.

Tool Path Generation and Cutting Descriptions. There are five different tool paths involved in the thread milling operation of the thrilling process (stages 4 to 6 in Fig. 1). These five different paths are defined as: (1) pre-run-in from point $O$ to $J$, (2) run-in from $J$ to $K$, (3) thread milling from $K$ to $K$ itself passing through $L$ and $M$, (4) run-out from $C$ back to $B$, and (5) post-run-out to the initial position, as shown in Fig. 4(a). The five paths in the three dimensional space are shown in Fig. 4(b). For a specific time $t, \theta_{t}(t)$ indicates the angular location of the tool center with respect to the absolute $X-Y-Z$ reference coordinate frame and $\theta(t)$ represents the angular rotation of the tool about its own axis (Fig. 4(a)). Note that $\theta_{t}(t)$ and $\theta(t)$ are in the opposite directions. While the tool moves in the counter-clockwise direction, the tool rotates in the clockwise direction, resulting in climb milling during the thread milling operation. Note that, in this case, point $B$ is located to the left of the $X-Y$ axis. If the conventional milling is desired, the tool motion should be in the clockwise direction, provided that the tool rotates in the clockwise direction.

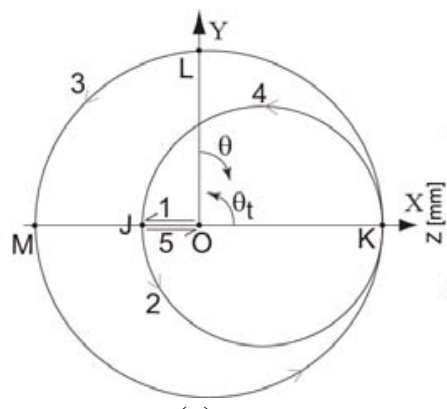

(a)

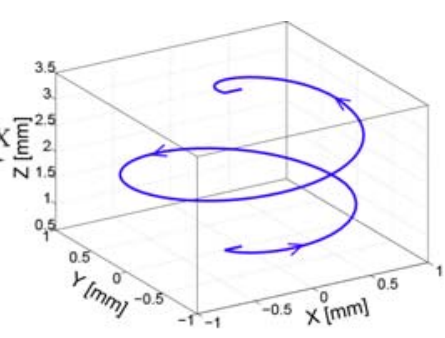

(b)
Figure 4. Tool paths involved in thread milling operation

Once the tool retracts a third of the thread pitch $p$ after drilling (stage 3 in Fig. 1 at which no cutting occurs), it moves in the negative X-direction (path 1 Fig. 4(a)) in by the distance of the difference between the milling cutting edge radius $\left(r_{m}\right)$ and the thread milling cutting edge outside radius $\left(r_{o}\right)$, i.e., $r_{m}-$ $r_{o}$. Cutting starts during this motion only by the milling cutting edge. Cutting by the thread milling cutting edge starts subsequently during the half-circular, helical, run-in motion in 
the counter-clockwise direction (path 2 in Fig. 4). The radius of the circular run-in motion $\left(r_{i n}\right)$ is given as

$$
r_{i n}=r_{m}-r_{o}+\frac{h_{t}}{2} \text {. }
$$

The circular motion at this radius ensures that the radial depth of cut gradually increases as the tool follows the run-in path, and at the end of the half-circular helical path, the thread is fully engaged in the workpiece, resulting in the radial depth of cut $\left(d_{r}\right)$ for the milling cutting edge as $d_{r}=h_{t}+r_{m}-r_{o}$ and for the thread milling cutting edge as $d_{r}=r_{t}(\mathrm{z})-r_{i}$. The tool moves up in the Z-direction half the pitch during the run-in motion.

During the thread milling stage (path 3 in Fig. 4(a)), the tool moves helically for one complete revolution at the radius same as the radial depth of cut for the milling cutting edge $\left(r_{t h}\right.$ $\left.=d_{r}=h_{t}+r_{m}-r_{o}\right)$. The threads are generated in the workpiece during this stage. The cutting edges are fully engaged in the workpiece for the first half of the revolution. However, for the second half, the thread milling cutting edges now cut the incomplete threads in the workpiece generated by the previous cutting edges during the run-in stage. The milling cutting edge cuts over these incomplete threads generated by the very bottom thread milling cutting edges. Thus, for the second half of the revolution, the radial depth of cut for each disk element of the cutting edge (as shown in Fig. 2) gradually decreases.

The thread milling cutting edges do not cut during the runout stage (path 4 in Fig. 4(a)) because the cutting edges now follow the threads generated by the previous cutting edges. But, cutting occurs by the milling cutting edge as it cuts over the threads generated. The radius of curvature during the runout motion is the same as that during the run-in motion $\left(r_{\text {out }}=\right.$ $\left.r_{i n}\right)$. After the run-out stage, the tool moves back to the center (post-run-out motion) and no cutting occurs during this motion.

In order to determine the cutting edge positions for chip thickness development, the positions of the tool center $\left(p_{c X}(t)\right.$, $\left.p_{c Y}(t), p_{c Z}(t)\right)$ along the tool path during the thread milling are needed. For the tool paths from 2 to $4, \theta_{t}(t)$ varies from $\pi$ to $5 \pi$. For simplicity, the time variable will be suppressed from the equations. The tool center $X$ and $Y$ positions for paths 2 and 4 can be obtained as

$$
p_{c X}=-\left(r_{m}-r_{o}\right)+r_{i n}\left(1+\cos \theta_{t}\right), \quad p_{c Y}=r_{i n} \sin \theta_{t}
$$

and the $X$ and $Y$ positions for path 3 are given by

$$
p_{c X}=r_{t h} \cos \theta_{t}, \quad p_{c Y}=r_{t h} \sin \theta_{t} .
$$

The $Z$ position of the tool center for the paths 2 to 4 can be obtained from

$$
p_{c Z}=h_{t} \frac{\left(\theta_{t}-\pi\right)}{2 \pi} \text {. }
$$

Tool center trajectory for the 5 paths is shown in Fig. 4(b), and Fig. 5 shows those of the cutting edges during the thread milling operation. The tool center path in Fig. 4(b) causes the cutting edges to move as shown in Fig. 5, leading to thread generation in the workpiece.

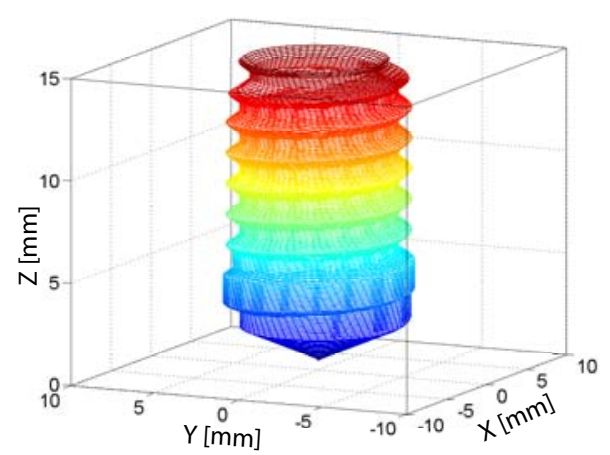

Figure 5. Path trajectories for cutting edges

Chip Thickness Model Development. During the thread milling operation, as the tool rotates about its own axis and follows the tool paths described above, the tool center angular location $\left(\theta_{t}\right)$ and the rotational angle $(\theta)$ changes simultaneously. As shown in Fig. 6 for an arbitrary disk element of a two-fluted tool, if the tool is initially at a given angular location $\left(\theta_{t, i}\right)$ or at point $A$ and the tool rotates by the amount of $\theta_{p}=2 \pi / N_{f}$ about its own axis, the tool center moves by the amount of the feed per tooth $\left(f_{t}\right)$. Simultaneously, the tool center revolves around the center of the drilled hole and the new tool center angular location is denoted as $\theta_{t, i}$. The position of the tool axis at the angular location $\theta_{t, i}$ is represented by the point $A^{\prime}$. Thus, the tool moves from point $A$ to point $A^{\prime}$ after a half revolution and to point $\mathrm{B}$ after a complete revolution. The distance from $A$ to $A^{\prime}$ is equal to the feed per tooth $\left(f_{t}\right)$ and from $A$ to $B$ is equal to the feed per revolution $\left(f_{r}\right)$. The coordinate frame $X-Y-Z$ is the reference frame at the center of the drilled hole $O$, and the local coordinate frame for $B$ is the $x-y-z$ coordinate frame, which is a rotating frame. Figure 6 shows both coordinate frames and also shows the tangential $\left(F_{t}\right)$ and radial $\left(F_{r}\right)$ forces acting on the cutting edge at the rotational angle $\theta$ when the tool is at point $B$. The chip load taken by the cutting edge is indicated by the shaded region.

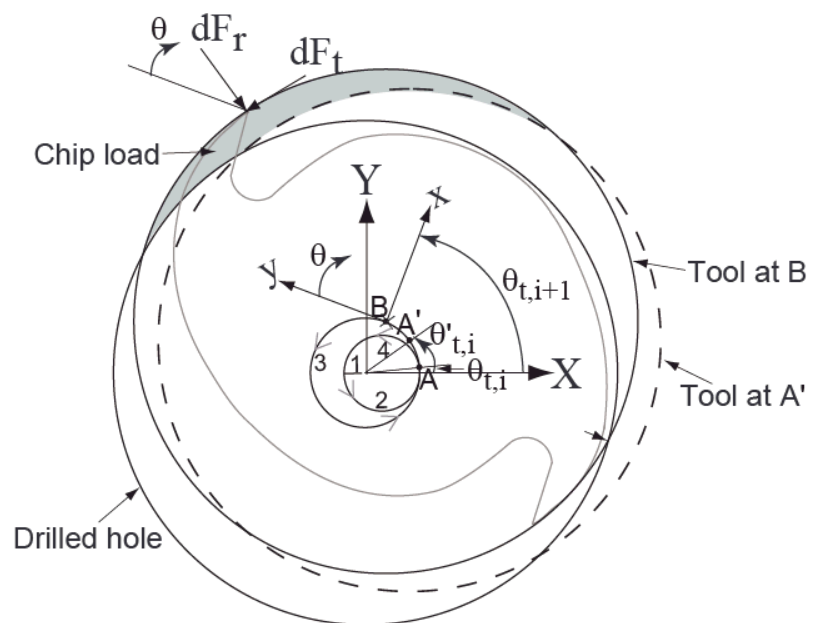

Figure 6. Chip load and coordinate frames during thread milling operation 
Figure 7 shows the details of geometry parameters associated for chip thickness model development. The radius of the tool center location with respect to the $X-Y-Z$ reference frame is denoted as $r_{c}$, and the radius of the hole surface for the disk element, represented by the line connecting the points $O$ and $Q$, is denoted as $r_{q}\left(\theta_{t}, z+p\right)$. Note that initially, during the first two paths of the thread milling operation, the radius of the hole surface is equal to the radius of the milling cutting edge, i.e., $r_{q}=r_{m}$. However, during the third path, the cutting edge now cuts over the area previously cut during the first two paths. Figure 8 shows the area of cut during each path of the thread milling operation. As shown, starting from the point $D$ during the third path, the cutting edge now cuts over the area cut from the previous paths. Thus, the radius of the hole surface $r_{q}\left(\theta_{t}, z\right)$ can be written as

$$
r_{q}\left(\theta_{t}, z\right)=\left\{\begin{array}{cc}
r_{m} & \theta_{t} \leq \frac{5 \pi}{2} \\
r_{t}(z)+\left(r_{m}-r_{i}\right) \sin \left(\frac{\theta_{t}}{3}-\frac{\pi}{6}\right) & \frac{5 \pi}{2}<\theta_{t} \leq 4 \pi . \\
r_{t}(z)+\left(r_{m}-r_{i}\right) & \theta_{t}>4 \pi
\end{array}\right.
$$

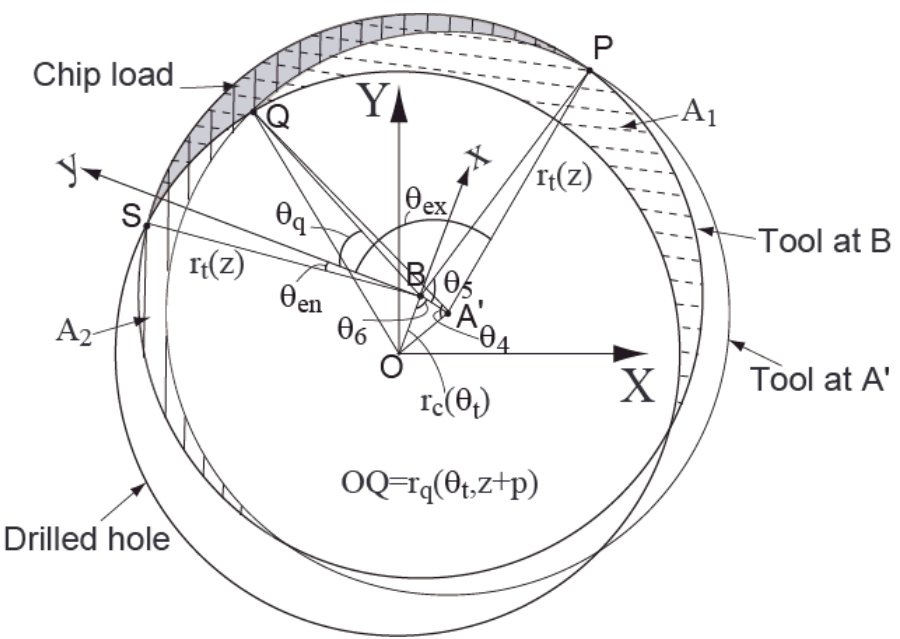

Figure 7. Geometry parameters for chip thickness model development

Note that because the paths from 2 to 4 are helical paths and thus the tool moves up as $\theta_{t}$ is increased, during the path 3 , the cutting edge cuts over the surface previously cut by the cutting edge one pitch higher than the current. This is why the radius of the hole surface in Fig. 7 is written as $r_{q}\left(\theta_{t}, z+p\right)$, where $p$ is the thread pitch. After the path 3 , the cutting edge does not cut but follows through the threads generated by the one-pitch-higher cutting edge. The only cutting edge that engages in cutting during the path 4 is the milling cutting edge because it is now positioned one pitch higher and cuts over the thread generated.

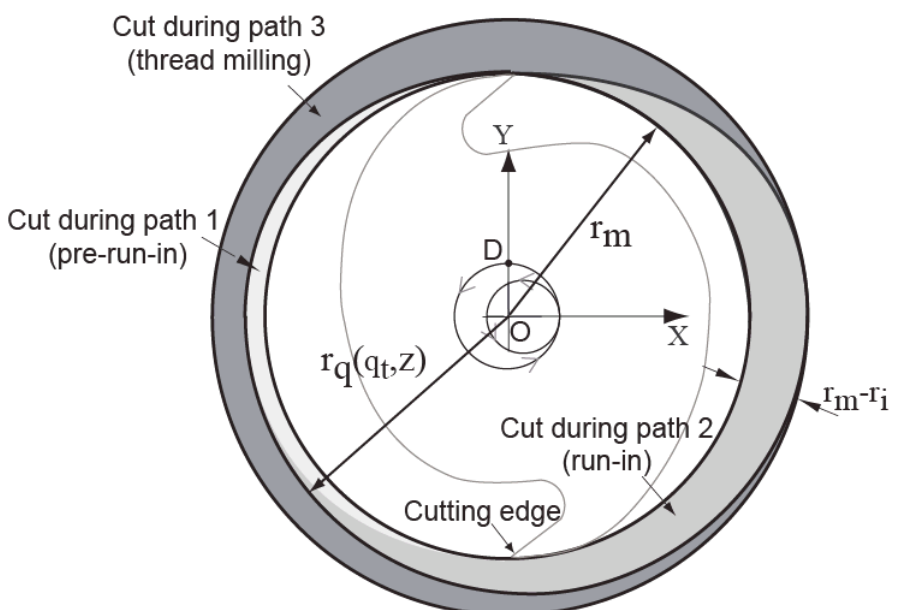

Figure 8. Areas of cut during each path of the thread milling operation

The points $P$ and $S$ in Fig. 7 represent the entry point and exit point of the cutting edge. The chip load is taken between the entry and exit angles and it is the intersection of the hatched areas with solid and dashed line. The entry and exit angles can be written as

$$
\begin{aligned}
& \theta_{e n}=\theta_{4}-\frac{\pi}{2} \\
& \theta_{e x}=\frac{3 \pi}{2}-\theta_{5}-\theta_{6}
\end{aligned}
$$

where

$$
\begin{aligned}
& \theta_{4}=\cos ^{-1}\left[\frac{r_{c}\left(\theta_{t}\right)^{2}+r_{t}(z)^{2}-r_{q}\left(\theta_{t}, z\right)^{2}}{2 r_{c}\left(\theta_{t}\right) r_{t}(z)}\right] \\
& \theta_{5}=\cos ^{-1}\left[\frac{f_{t}}{2 r_{t}(z)}\right], \quad \theta_{6}=\cos ^{-1}\left[\frac{f_{t}}{2 r_{c}\left(\theta_{t}\right)}\right] .
\end{aligned}
$$

The maximum height of the hatched area with solid lines $\left(A_{2}\right)$ is the feed per tooth $\left(f_{t}\right)$ and the maximum height of the hatched area with dashed lines $\left(A_{1}\right)$ is the radial depth of cut $\left(d_{r}\right)$. The radial depth of cut is expressed as

$$
d_{r}\left(\theta_{t}, z\right)=r_{t}(z)+r_{c}\left(\theta_{t}\right)-r_{q}\left(\theta_{t}, z+p\right),
$$

and the chip thickness for the $j^{\text {th }}$ tooth can be obtained as

$$
\operatorname{tc}\left(\theta_{j}, z\right)= \begin{cases}d_{r}\left(\theta_{t}, z\right) \sin \left(\frac{\pi\left(\theta_{j}-\theta_{e n}\right)}{\pi-2 \theta_{e n}}\right) & \theta_{e n}<\theta_{j} \leq \theta_{q} \\ f_{t} \sin \left(\theta_{j}+\frac{\pi}{2}-\frac{\pi-2 \theta_{6}}{2}\right) & \theta_{q}<\theta_{j} \leq \theta_{e x}\end{cases}
$$

where

$$
\theta_{j}=\theta-(j-1) \frac{2 \pi}{N_{f}}-z \frac{\tan \left(\alpha_{h}\right)}{r_{t}(z)} .
$$


Cutting Force Model Development. The tangential $\left(d F_{t}\right)$ and radial $\left(d F_{r}\right)$ cutting forces acting on a differential flute element with height $d z$, as shown in Fig. 6, can be modeled as follows,

$$
\begin{aligned}
& d F_{t}=K_{t} t c\left(\theta_{j}, z\right) d z \\
& d F_{r}=K_{r} t c\left(\theta_{j}, z\right) d z \\
& d F_{z}=K_{z} t c\left(\theta_{j}, z\right) d z
\end{aligned}
$$

where $K_{t}, K_{r}$, and $K_{z}\left[\mathrm{~N} / \mathrm{mm}^{2}\right]$ are specific tangential, radial, and axial cutting constants or energies, which represent the energy required to shear or deform the workpiece. These coefficients need to be identified through experimental calibration. The tangential and radial forces can be transformed to the $x-y-z$ rotating frame as

$$
\begin{aligned}
& d F_{x}=-\left(K_{r} \sin \theta_{j}+K_{t} \cos \theta_{j}\right) t c\left(\theta_{j}, z\right) d z \\
& d F_{y}=-\left(K_{r} \cos \theta_{j}-K_{t} \sin \theta_{j}\right) t c\left(\theta_{j}, z\right) d z
\end{aligned} .
$$

The $X-Y$ forces in the reference frame then can be expressed as

$$
\begin{aligned}
& d F_{X}=d F_{x} \cos \theta_{t}-d F_{y} \sin \theta_{t} \\
& d F_{Y}=d F_{x} \sin \theta_{t}+d F_{y} \cos \theta_{t}
\end{aligned} .
$$

In order to determine the torque with respect to the reference frame, the forces acting on the cutting edge during the thread milling operation need to be examined carefully as shown in Fig. 9. Considering the force components that are tangential to the hole being threaded, the torque with respect to the reference frame can be computed as

$$
d T_{q}=d F_{t} r_{t q}\left(\theta_{t}, z\right) \cos \left(\theta_{t q}\right)-d F_{r} r_{t q}\left(\theta_{t}, z\right) \sin \left(\theta_{t q}\right)
$$

where

$$
\begin{aligned}
& r_{t q}=\sqrt{r_{c}\left(\theta_{t}\right)^{2}+r_{t}(z)^{2}-2 r_{c}\left(\theta_{t}\right) r_{t}(z) \cos \left(\theta_{j}+\theta_{t}-\pi / 2\right)} \\
& \theta_{t q}=\sin ^{-1}\left(\frac{r_{c}\left(\theta_{t}\right) \sin \left(\pi / 2+\theta_{j}\right)}{r_{t q}}\right) .
\end{aligned}
$$

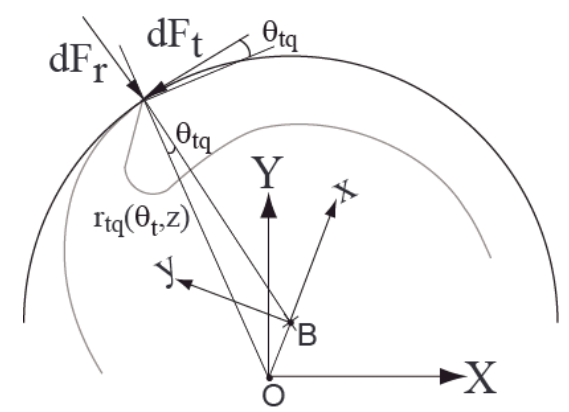

Figure 9. Forces acting on cutting edges with respect to the reference frame

\section{EXPERIMENTAL VALIDATION OF THE MODEL}

Setup and Thread Milling Experiments. Experiments were conducted on Mori Seiki TV30 CNC milling center. A Kistler four-axis dynamometer (9272) was used to measure both drilling and thread milling forces. LabView software was used for data acquisition. The experiments were conducted with an Emuge thriller of size M10x1.5 standard threads. Aluminum 6061 was used for the experiments. Castrol 6519 at 5\% dilution was used as cutting fluid. The helix angle was measured using an optical microscope (Hirox CX-10C) and TechDig software. Table 1 shows the thriller geometry.

Table 2 shows the cutting conditions for the experiments. Five threads were generated during the thrilling process. The experiment numbers from 1 to 4 are used for calibration of the cutting coefficients, and experiment numbers 5 and 6 are used for validation of the model. Figure 10 shows the torque and thrust during the thread milling operation at the spindle speed of $2000 \mathrm{rpm}$ and the feedrate of $0.02 \mathrm{~mm} / \mathrm{rev}$. The forces during the run-in loop, thread milling, and run-out loop are also shown in Fig. 10. The forces in the $X$ - and $Y$-directions are shown in Fig. 11. Note that the forces in the $X$ - and $Y$ directions (Fig. 11) are quite large, compared to the torque (Fig. 10), indicating that radial forces are relatively large. Thus, understanding of lateral tool vibrations in terms of forced vibration and chatter will be important for thread milling processes.

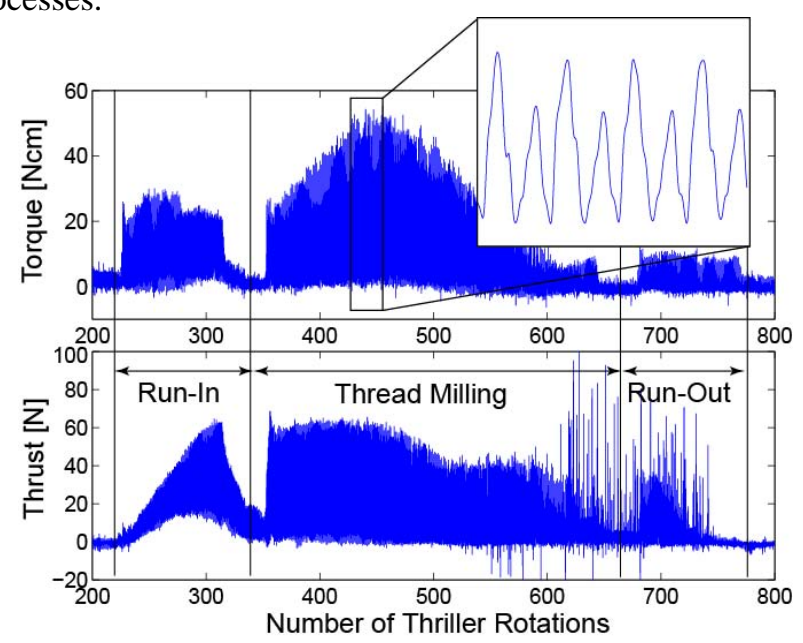

Figure 10. Typical thread milling torque and thrust

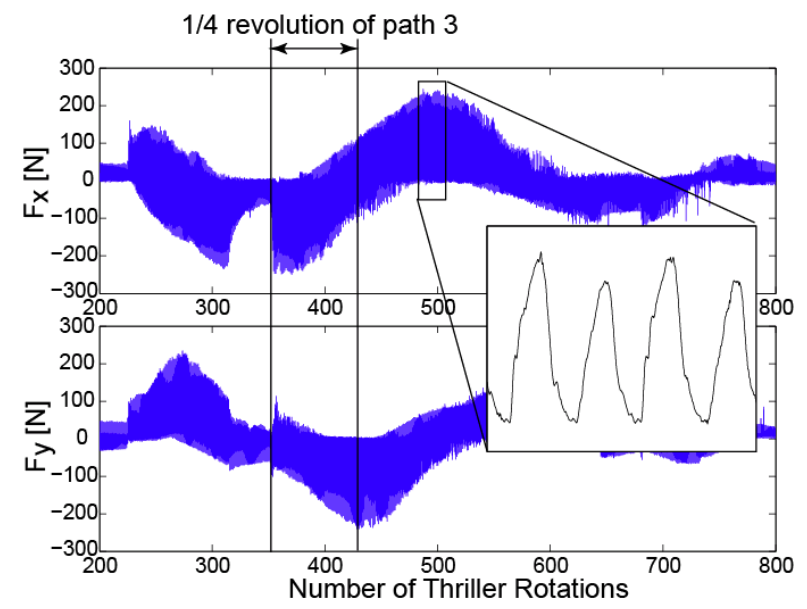

Figure 11. Thread milling forces in $\mathrm{X}$ - and $\mathrm{Y}$-directions 
Table 1. Thriller Geometry

\begin{tabular}{|c|c|}
\hline Geometry & Value \\
\hline Point angle $\kappa$ & $140^{\circ}$ \\
\hline Cutting lips height $h_{d}$ & $1.64 \mathrm{~mm}$ \\
\hline Milling cutting edge height $h_{m}$ & $1.35 \mathrm{~mm}$ \\
\hline Milling cutting edge diameter $d_{d}$ & $8.5 \mathrm{~mm}$ \\
\hline Helix angle $\alpha_{h}$ & $35^{\circ}$ \\
\hline Thread pitch $p$ & $1.5 \mathrm{~mm}$ \\
\hline Thread height $h_{t}$ & $0.75 \mathrm{~mm}$ \\
\hline Thread outside diameter $d_{o}$ & $8.2 \mathrm{~mm}$ \\
\hline Thread inside diameter $d_{i}$ & $5.2 \mathrm{~mm}$ \\
\hline
\end{tabular}

Table 2. Cutting conditions for thread milling experiments

\begin{tabular}{|c|c|c|}
\hline Exp. \# & Speed [rpm] & Feed [mm/rev] \\
\hline 1 & 1000 & 0.01 \\
\hline 2 & 1000 & 0.02 \\
\hline 3 & 2000 & 0.01 \\
\hline 4 & 2000 & 0.02 \\
\hline 5 & 1500 & 0.015 \\
\hline 6 & 1500 & 0.01 \\
\hline
\end{tabular}

Calibration of Cutting Coefficients. In order to predict the cutting forces, the specific cutting energies are required. The estimation of the specific cutting energies requires the determination of the coefficients. These coefficients are typically estimated from experiments for a given combination of workpiece and tool material. The tangential, radial, and axial cutting constants or energies, $K_{t}, K_{r}$, and $K_{z}$, respectively, are represented by the following equations,

$$
\begin{aligned}
& \ln \left(K_{t}\right)=a_{0}+a_{1} \ln \left(f_{t}\right)+a_{2} \ln (N) \\
& \ln \left(K_{r}\right)=b_{0}+b_{1} \ln \left(f_{t}\right)+b_{2} \ln (N) \\
& \ln \left(K_{z}\right)=c_{0}+c_{1} \ln \left(f_{t}\right)+c_{2} \ln (N)
\end{aligned}
$$

where $f_{t}$ is feed per tooth (mm/tooth) and $N$ is the rotational speed (rpm), $a_{0-2}, b_{0-2}$, and $c_{0-2}$ are cutting coefficients for the corresponding cutting energies. The forces in the $X$ - and $Y$ directions are used for calibration of the tangential $\left(K_{t}\right)$ and radial $\left(K_{r}\right)$ cutting energies and the $Z$-direction force is used for calibration of the axial $\left(K_{z}\right)$ cutting energy. The forces in the $\mathrm{X}$ and Y-directions can be rewritten as

$$
\begin{aligned}
d F_{X}= & K_{t}\left(-\cos \theta_{j} \cos \theta_{t}-\sin \theta_{j} \sin \theta_{t}\right) t c\left(\theta_{j}, z\right) d z \\
& +K_{r}\left(\cos \theta_{j} \sin \theta_{t}-\sin \theta_{j} \cos \theta_{t}\right) t c\left(\theta_{j}, z\right) d z \\
d F_{Y}=K_{t}\left(\sin \theta_{j} \cos \theta_{t}-\cos \theta_{j} \sin \theta_{t}\right) t c\left(\theta_{j}, z\right) d z & \\
& +K_{r}\left(-\sin \theta_{j} \sin \theta_{t}-\cos \theta_{j} \cos \theta_{t}\right) t c\left(\theta_{j}, z\right) d z
\end{aligned}
$$

or

$$
\begin{aligned}
& d F_{X}=K_{t} d \alpha_{1}+K_{r} d \alpha_{2} \\
& d F_{Y}=K_{t} d \beta_{1}+K_{r} d \beta_{2}
\end{aligned}
$$

where

$$
\begin{aligned}
& d \alpha_{1}=\left(-\cos \theta_{j} \cos \theta_{t}-\sin \theta_{j} \sin \theta_{t}\right) t c\left(\theta_{j}, z\right) d z \\
& d \alpha_{2}=\left(\cos \theta_{j} \sin \theta_{t}-\sin \theta_{j} \cos \theta_{t}\right) t c\left(\theta_{j}, z\right) d z \\
& d \beta_{1}=\left(\sin \theta_{j} \cos \theta_{t}-\cos \theta_{j} \sin \theta_{t}\right) t c\left(\theta_{j}, z\right) d z \\
& d \beta_{2}=\left(-\sin \theta_{j} \sin \theta_{t}-\cos \theta_{j} \cos \theta_{t}\right) t c\left(\theta_{j}, z\right) d z
\end{aligned}
$$

For calibration of the cutting coefficients, the average forces $\left(\bar{F}_{X}\right.$ and $\left.\bar{F}_{Y}\right)$ are used and the tangential and radial cutting energies at each cutting condition can be found as

$$
K_{t}=\frac{\bar{F}_{X} \bar{\beta}_{2}-\bar{F}_{Y} \bar{\alpha}_{2}}{\bar{\alpha}_{1} \bar{\beta}_{2}-\bar{\alpha}_{2} \bar{\beta}_{1}}, \quad K_{r}=\frac{\bar{F}_{X} \bar{\beta}_{1}-\bar{F}_{Y} \bar{\alpha}_{1}}{\bar{\alpha}_{2} \bar{\beta}_{1}-\bar{\alpha}_{1} \bar{\beta}_{2}}
$$

where the bars represent the average and the averages of $\alpha_{1}, \alpha_{2}$, $\beta_{1}$, and $\beta_{2}$ are obtained from simulation. The axial cutting energy $\left(K_{z}\right)$ can simply be determined from the average thrust or Z-direction force from Eq. (13).

As can be seen in Fig. 11, because the forces in the $X$ - and $Y$-directions fluctuate around zero, the average would be close to zero and accurate estimation of the tangential and radial cutting energies would be difficult. Thus, the average of the forces in the first quarter revolution of the path 3 (thread milling in Fig. 4(a)) is used for calibration of the coefficients as shown in Fig. 11. In order to clearly see the beginning and end of the path 3, a short delay was introduced after the run-in loop and after the run-out loop during the thread milling experiments.

Table 3 shows the results of the calibration and the values of the cutting coefficients.

Table 3. Calibrated values of cutting coefficients

\begin{tabular}{|c|c|c|c|c|c|}
\hline \multicolumn{5}{|c|}{ Cutting coefficients } \\
\hline$a_{0}$ & 6.8750 & $b_{0}$ & 6.5507 & $c_{0}$ & 6.2346 \\
\hline$a_{1}$ & -0.0556 & $b_{1}$ & -0.0142 & $c_{1}$ & 0.0069 \\
\hline$a_{2}$ & 0.2299 & $b_{2}$ & 0.2848 & $c_{2}$ & 0.2323 \\
\hline
\end{tabular}

Model Validation. With the calibrated cutting coefficients given in

Table 3, thread milling operations are simulated at the conditions for the experiments 5 and 6 in Table 2 for validation of the model. Figures 12 and 13 show comparison of the force profiles between experiments and simulations. Except for zero forces during the delay after the run-in loop and before the runout loop, the profiles of the experiments and simulations seem to match well. Average forces and torque are calculated during the first $1 / 4$ revolution of the path 3 (thread milling operation) and the comparison between experiments and simulations are given in Table 4. There is a close match in the average forces and torque between experiments and simulations (less than $12 \%$ error).

Note that there are several assumptions associated with the proposed thread milling force model and the errors between 
the experiments and simulations may be due to these assumptions. The model in this paper assumes that the tool and workpiece are rigid and no tool deflection, vibration, and the effect of the runout are considered in the modeling. The runout would also have a strong influence on the torque because the radius of the cutting edge with respect to the reference frame varies depending on the magnitude of the runout. However, since tool deflection and vibration, and runout are all present in the experiments, absence of these in the modeling may be why the actual torque is lower than the simulated result. The authors are in the process of investigating the influence of these factors on the thrilling process.

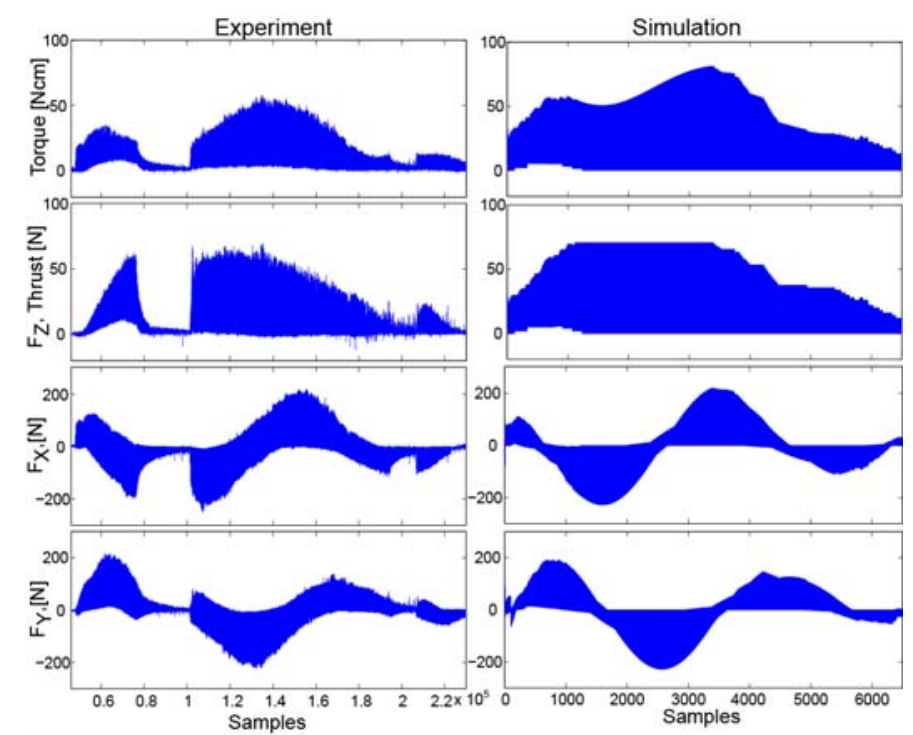

Figure 12. Comparison between experiment and simulation for validation when $N=1500 \mathrm{rpm}$ and $f_{r}=0.015 \mathrm{~mm} / \mathrm{rev}$

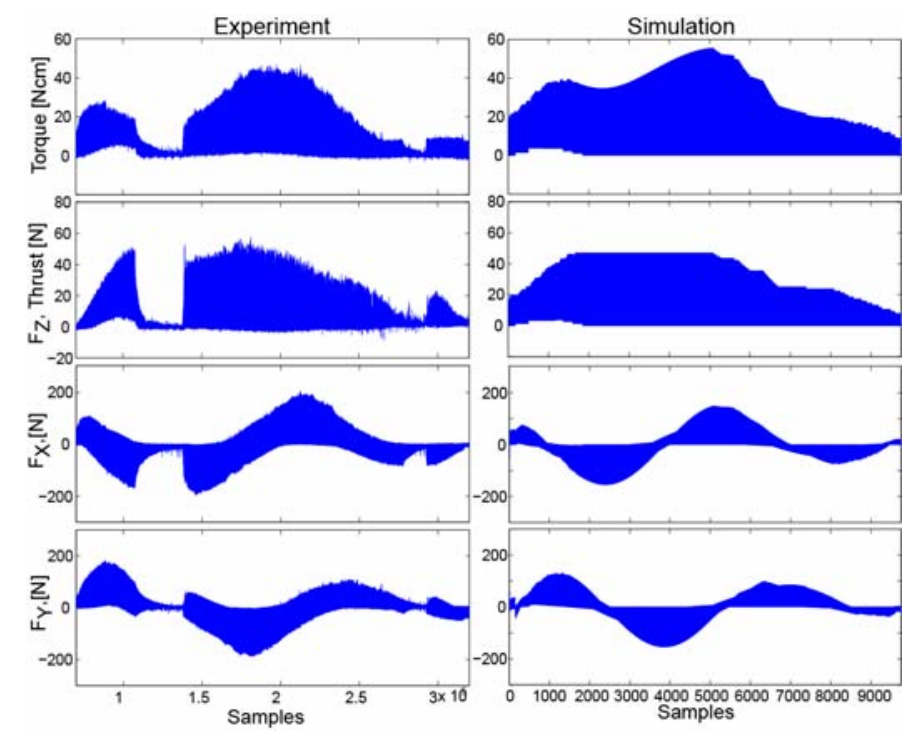

Figure 13. Comparison between experiment and simulation for validation when $N=1500 \mathrm{rpm}$ and $f_{r}=0.01 \mathrm{~mm} / \mathrm{rev}$
Table 4. Average forces and torque comparison between experiments and simulations

\begin{tabular}{|c|c|c|c|c|c|c|}
\hline & \multicolumn{3}{|c|}{ Exp. \#5 } & \multicolumn{3}{c|}{ Exp. \#6 } \\
\hline & Exp & Sim & \%error & Exp & Sim & \%error \\
\hline Torque $[N c m]$ & 18.90 & 21.35 & -11.48 & 14.60 & 14.67 & -8.27 \\
\hline Thrust $[\mathrm{N}]$ & 29.98 & 29.21 & 2.62 & 19.42 & 19.05 & 6.13 \\
\hline $\mathrm{F}_{\mathrm{X}}[\mathrm{N}]$ & -79.54 & -76.53 & 3.93 & -51.83 & -51.87 & 9.63 \\
\hline $\mathrm{F}_{\mathrm{Y}}[\mathrm{N}]$ & -35.54 & -32.67 & 8.80 & -22.10 & -22.12 & 3.96 \\
\hline
\end{tabular}

\section{ANALYSIS ON EFFECTS OF HELIX ANGLE AND NUMBER OF ENGAGED THREADS}

The model is now employed to demonstrate the effects of the helix angle and the number of threads generated on the forces and torque. For the analysis in this section, simulations are performed for the tool geometry given in Table 1 except for those that are being varied. The cutting conditions are at the feedrate of $0.015 \mathrm{~mm} / \mathrm{rev}$ and the spindle speed of $1500 \mathrm{rpm}$.

In order to study the effect of helix angle on cutting forces, simulations were conducted at four different helix angles $(0,15,30$, and 45 degrees). The average torques and thrusts and are computed from the simulation results. The average for all the stages is computed including the pre-run-in, run-in, and run-out paths. The peak torques and thrusts and peak-to-valley X-Y forces are also computed. The results are given in

\section{Table 5.}

Table 5. Average forces and torque comparison between experiments and simulations

\begin{tabular}{|c|c|c|c|c|}
\hline Helix [deg] & 0 & 15 & 30 & 45 \\
\hline \multicolumn{5}{|c|}{ Average torques and thrusts } \\
\hline Torque [Ncm] & 12.54 & 12.02 & 13.23 & 12.37 \\
\hline Thrust [N] & 11.97 & 11.47 & 12.85 & 11.90 \\
\hline \multicolumn{5}{|c|}{ Peak-to-valley torques and forces } \\
\hline Torque [Ncm] & 63.93 & 50.50 & 48.99 & 33.10 \\
\hline Thrust [N] & 66.69 & 54.24 & 54.91 & 39.13 \\
\hline $\mathrm{F}_{\mathrm{X}}[\mathrm{N}]$ & 396.12 & 332.61 & 314.69 & 222.18 \\
\hline $\mathrm{F}_{\mathrm{Y}}[\mathrm{N}]$ & 418.75 & 303.35 & 306.80 & 212.92 \\
\hline
\end{tabular}

The simulation results show that, though the average torque and thrust do not vary much, the peak-to-valley values decrease as helix angle is increased. As helix angle is increased to 45 degrees, the peak-to-valley torque and forces decrease to a half of the values at zero helix angle. This shows that higher helix angle is preferable in thrilling because lower peak forces are involved, leading to less tool vibrations. As mentioned above, the forces in the $\mathrm{X}-\mathrm{Y}$ directions are quite large unlike in tapping. Thus, tool deflections can lead to undercut of the 
threads and also tool vibrations will result in poor thread quality.

The milling cutting edge plays an important role in thrilling because it is what allows both the drilling and thread milling operations to be performed with a single tool. However, because of the presence of the milling cutting edge, generation of the thread cannot be performed in a multiple steps. In other words, once a hole is drilled with the milling cutting edge to a certain depth and threads are generated through thread milling operation, that particular threaded hole cannot be modified because the hole has a groove made by the milling cutting edge at the bottom. If a threaded hole with a large depth is needed, it needs to be generated in a single step with a thrilling tool. Therefore, there is a concern with increased tool vibration due to increased forces as the number of engaged threads is increased.

Figure 14 shows the peak-to-valley values at different number of engaged threads when $N=1500 \mathrm{rpm}$ and $f_{r}=0.015$ $\mathrm{mm} / \mathrm{rev}$. As can be seen, the forces increase linearly with the number of engaged threads. When six threads are engaged, the force in the Y-direction increases more than $800 \mathrm{~N}$. This shows that tool vibrations may be significant as more threads are engaged. Thus, in applications where long holes are required, care must be taken to examine the effects of tool vibrations on the thread quality.

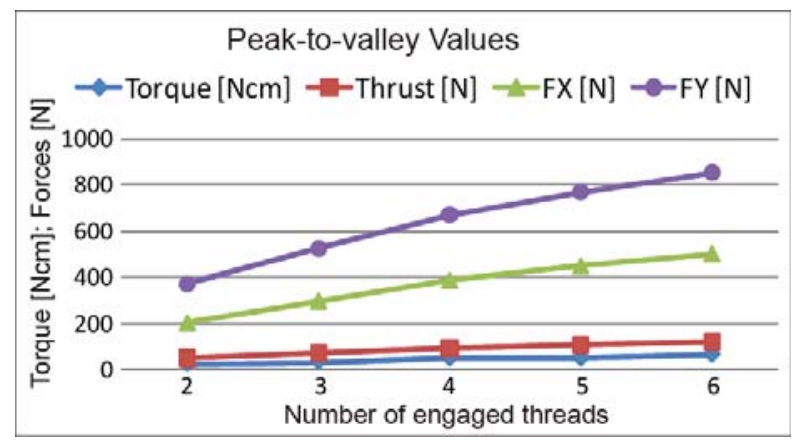

Figure 14. Peak-to-valley values at different number of engaged threads when $N=1500 \mathrm{rpm}$ and $f_{r}=0.015 \mathrm{~mm} / \mathrm{rev}$

\section{CONCLUSION}

The following conclusions can be drawn from this work:

1. A combined drilling and thread milling operation called thrilling has been investigated and a chip thickness and cutting force model have been developed for a thread milling operation with a thrilling tool. The model considers the complex geometry of a thrilling tool and the unique tool paths associated with the thread milling operation with a thrilling tool.

2. Calibration experiments have been conducted to estimate the cutting coefficients associated with specific cutting energies.

3. Experiments have been conducted to validate the developed model. Comparison of the average torque and forces between experiment and simulation results shows that the model predicts the experimental results within $12 \%$ error.

4. The model has been used to analyze the effects of helix angle and number of engaged threads on the cutting forces. As helix angle is increased, the average forces do not vary much. However, the peak-to-valley values decrease significantly as helix angle is increased.

5. Due to the presence of the milling cutting edge, all the threads need to be generated in a single step with a thrilling tool. The study on the effects of number of engaged threads on the forces shows that forces linearly increase with the number of engaged threads. Thus, care must be taken in applications where long thread holes are required due to increased forces and consequently increased vibrations.

\section{ACKNOWLEDGMENTS}

This research is based upon the work conducted at the Center of Machine Tools Systems Research at the University of Illinois at Urbana-Champaign (UIUC). The authors gratefully acknowledge the support of Shiv Kapoor and Richard DeVor at UIUC. The authors also acknowledge the support of Brazilian Research Councils CNPq and FAPERJ.

\section{REFERENCES}

[1] MMS Online (Modern Machine Shop Online), http://www.mmsonline.com/articles/019603.html.

[2] Cao, T. and Sutherland, J.W., 2002 "Investigation of thread tapping load characteristics through mechanistic modeling and experimentation," International Journal of Machine Tools and Manufacture, 42(14), pp. 1527-1538.

[3] Ivanina, I.V., 2005 "Influence of parameters of the cutting part of taps on threading accuracy," Measurement Techniques, 48(10), pp. 990-4.

[4] Warrington, C., Kapoor, S.G., and DeVor, R.E., 2005 "Experimental investigation of thread formation in form tapping," Journal of Manufacturing Science and Engineering, Transactions of the ASME, 127(4), pp. 829836.

[5] Chowdhary, S., Kapoor, S.G., Ozdoganlar, O.B., and DeVor, R.E. 2002, "Modeling and analysis of internal thread forming," NAMRC XXX, May 21-24 2002, West Lafayette, ID.pp. 1-8.

[6] Smith, G.T., 1989, "Advanced machining: the handbook of cutting technology. 1989, Springer/IFS Publications.

[7] Araujo, A.C., Silveira, J.S., Jun, M.B.G., Kapoor, S.G., and DeVor, R.E., 2006 "A model for thread milling cutting forces," International Journal of Machine Tools \& Manufacture, 46, pp. 2057-2065.

[8] Dogra, A.P.S., Kapoor, S.G., and DeVor, R.E., 2002 "Mechanistic model for tapping process with emphasis on process faults and hole geometry," Journal of Manufacturing Science and Engineering, Transactions of the ASME, 124(1), pp. 18-25. 
[9] Araujo, A.C., Jun, M.B.G., Kapoor, S.G., and DeVor, R.E., 2007 "Experimental Investigation of a Combined Drilling and Thread Milling Process: Thrilling," Transactions of NAMRI/SME, XXXV, pp. 518-527.

[10] Emuge, http://www.emuge.com/carbide_thread/bgf.html.

[11] Altintas, Y., 2000, "Manufacturing Automation: Metal Cutting Mechanics, Machine Tool Vibrations, and CNC Design. 2000, Cambridge University Press.

[12] Furness, R.J., Wu, C.L., and Ulsoy, A.G. 1992, "Dynamic modeling of the thrust force and torque for drilling, Chicago, IL, USA.pp. 384-90.

[13] Strenkowski, J.S., Hsieh, C.C., and Shih, A.J., 2004 "An analytical finite element technique for predicting thrust force and torque in drilling," International Journal of Machine Tools \&amp; Manufacture, 44(12-13), pp. 141321.

[14] Yongping, G., Cheng, L., and Ehmann, K.F., 2005 "Dynamics of initial penetration in drilling: part 1mechanistic model for dynamic forces," Transactions of the ASME. Journal of Manufacturing Science and Engineering, 127(2), pp. 280-8.

[15] Chandrasekharan, V., Kapoor, S.G., and DeVor, R.E., 1998 "Mechanistic model to predict the cutting force system for arbitrary drill point geometry," Journal of Manufacturing Science and Engineering, Transactions of the ASME, 120(3), pp. 563-570.

[16] Altintas, Y. and Weck, M., 2004 "Chatter stability of metal cutting and grinding," CIRP Annals Manufacturing Technology, 53(2), pp. 619-642. 